\title{
High-energy X-ray diffraction study on the temperature-dependent mechanical stability of retained austenite in low-alloyed TRIP steels
}

\author{
R. Blondé ${ }^{\mathrm{a}, \mathrm{b}, *}$, E. Jimenez-Melero ${ }^{\mathrm{a}}$, L. Zhao ${ }^{\text {b,c }}$, J.P. Wright ${ }^{\mathrm{d}}$, E. Brück ${ }^{\mathrm{a}}$, \\ S. van der Zwaag ${ }^{\mathrm{e}}$, N.H. van Dijk ${ }^{\mathrm{a}}$ \\ ${ }^{a}$ Fundamental Aspects of Materials and Energy, Faculty of Applied Sciences, Delft University of Technology, Mekelweg 15, 2629 JB Delft, The Netherlands \\ ${ }^{\mathrm{b}}$ Materials Innovation Institute, Mekelweg 2, $2628 \mathrm{CD}$ Delft, The Netherlands \\ ${ }^{\mathrm{c}}$ Department of Materials Science and Engineering, Delft University of Technology, Mekelweg 2, 2628 CD Delft, The Netherlands \\ ${ }^{\mathrm{d}}$ European Synchrotron Radiation Facility, 6 Rue Jules Horowitz, BP 220, 38043 Grenoble Cedex, France \\ ${ }^{\mathrm{e}}$ Novel Aerospace Materials Group, Faculty of Aerospace Engineering, Delft University of Technology, Kluyverweg 1, 2629 HS Delft, The Netherlands
}

Received 26 September 2011; accepted 11 October 2011

Available online 22 November 2011

\begin{abstract}
The stability of the retained austenite has been studied in situ in low-alloyed transformation-induced-plasticity (TRIP) steels using high-energy X-ray diffraction during tensile tests at variable temperatures down to $153 \mathrm{~K}$. A detailed powder diffraction analysis has been performed to probe the austenite-to-martensite transformation by characterizing the evolution of the phase fraction, load partitioning and texture of the constituent phases simultaneously. Our results show that at lower temperatures the mechanically induced austenite transformation is significantly enhanced and extends over a wider deformation range, resulting in a higher elongation at fracture. Low carbon content grains transform first, leading to an initial increase in average carbon concentration of the remaining austenite. Later the carbon content saturates while the austenite still continues to transform. In the elastic regime the probed $\{h k l\}$ planes develop different strains reflecting the elastic anisotropy of the constituent phases. The observed texture evolution indicates that the austenite grains oriented with the $\{200\}$ plane along the loading direction are transformed preferentially as they show the highest resolved shear stress. For increasing degrees of plastic deformation the combined preferential transformation and grain rotation results in the standard deformation texture for austenite with the $\{111\}$ component along the loading direction. The mechanical stability of retained austenite in TRIP steel is found to be a complex interplay between carbon concentration in the austenite, grain orientation, load partitioning and temperature.
\end{abstract}

(C) 2011 Acta Materialia Inc. Published by Elsevier Ltd. All rights reserved.

Keywords: TRIP-assisted steel; Metastable phases; Martensitic transformation; Synchrotron radiation; Crystal orientation

\section{Introduction}

Low-alloyed transformation-induced-plasticity (TRIP) steels were developed in the late 1980s [1-4] and have

\footnotetext{
* Corresponding author at: Fundamental Aspects of Materials and Energy, Faculty of Applied Sciences, Delft University of Technology, Mekelweg 15, 2629 JB Delft, The Netherlands. Tel.: +31 (0)15 2783793; fax: $+31(0) 152788303$.

E-mail address: R.J.P.Blonde@tudelft.nl (R. Blondé).
}

attracted significant interest for automotive applications due to their outstanding combination of high strength and formability [5-7]. A typical TRIP steel microstructure contains three phases at room temperature: ferrite, bainite and metastable austenite $[8,9]$. The remarkable mechanical properties of this material are attributed to the multiphase microstructure as well as to the transformation of the soft metastable austenite phase into the hard martensite phase upon activation by mechanical and/or thermal stimuli. This phenomenon, called the TRIP effect, increases the 
work-hardening rate during plastic deformation and delays necking $[10,11]$.

A lot of effort has been devoted in recent years to maximize and tune the retention of austenite at room temperature in order to enhance the TRIP effect [12-15]. In order to create a sufficient amount of retained austenite in the TRIP microstructure, a three-step heat treatment (intercritical annealing, bainitic holding and finally quenching to room temperature) is imposed [16]. This heat treatment is only effective if a sufficient concentration of alloying elements (such as $\mathrm{Si}, \mathrm{Al}$ and $\mathrm{P}$ ) retarding the cementite formation during the bainitic holding treatment is present $[17,18]$. An optimized composition and heat treatment leads to a retained austenite fraction of $10-15 \%$. The carbon concentration of the retained austenite is about six to nine times the nominal carbon concentration, but varies from grain to grain [19-21].

In previous in situ studies the average retained austenite behavior was studied either as a function of the undercooling (defining the thermal stability) [22-24] or as a function of the applied load at room temperature (defining the mechanical stability) [25-32]. In these studies some attention was paid to the behavior of the non-transforming ferritic phase as well. These experimental results led to the development of micromechanical models for the TRIP multiphase microstructure [33-36]. An accurate prediction of the material's mechanical response at variable temperatures requires detailed knowledge about the interplay between the transformation behavior, the local load redistribution between the phases, the texture evolution and the deformation behavior of the non-transforming ferritic matrix as a function of both temperature and uniaxial load.

Recent advances at synchrotron radiation sources have provided material scientists with intense high-energy X-ray beams of micron dimensions that are a valuable tool for in situ studies during the thermomechanical processing of advanced engineering materials [37]. In our previous synchrotron X-ray diffraction studies we have probed the austenite transformation behavior in the bulk TRIP microstructure during deformation at room temperature [38] and during cooling down to $100 \mathrm{~K}[21,24,39,40]$. We found that the austenite stability depends on both the local carbon content and the grain size. In this work, a complete in situ characterization of the combined thermal and mechanical stability of the retained austenite has been performed by high energy synchrotron X-ray diffraction (XRD) during temperature-dependent tensile tests. The interplay between tensile deformation, the orientation-dependent austenite to martensite transformation and grain rotation has been analyzed by a Rietveld refinement of the diffraction data characterizing the relevant phases and their textures simultaneously.

\section{Experimental methods}

\subsection{Sample preparation}

The chemical composition of the studied TRIP steel is shown in Table 1. Cylindrical dog-bone tensile specimens with a gauge length of $10 \mathrm{~mm}$ and a diameter of $1 \mathrm{~mm}$ were machined from hot rolled sheet material. The cylindrical axis of the samples was chosen parallel to the rolling direction (RD). A mark parallel to the normal direction of the sheet material was made on the top part of the cylindrical sample in order to keep track of the sample orientation. First, the samples were annealed in a salt bath for $30 \mathrm{~min}$ at an intercritical temperature of $1143 \mathrm{~K}$ in order to obtain equal fractions of austenite and ferrite. Then the samples were quenched in a second salt bath to a temperature of $673 \mathrm{~K}$ and held for $2 \mathrm{~min}$. During this holding time part of the intercritical austenite transformed into bainite and the remaining austenite was enriched in carbon. The carbon-enriched austenite remained in a metastable state after a final water quench to room temperature. This heat treatment yielded a multiphase microstructure composed of ferrite $(\alpha)$, bainite $\left(\alpha_{b}\right)$ and metastable austenite $(\gamma)$, as shown in the optical micrograph of Fig. 1.

\subsection{In situ high-energy X-ray diffraction}

The in situ XRD experiments were performed at the three-dimensional (3-D) X-ray diffraction microscope at the ID11 beam line of the European Synchrotron Radiation Facility (Grenoble, France). Fig. 2 shows the experimental setup used for the experiments. A monochromatic X-ray beam of $88 \mathrm{keV}$ (wavelength of $0.141 \AA$ ) and a beam size of $100 \times 100 \mu \mathrm{m}^{2}$ illuminated the cylindrical sample. For these high-energy X-rays the absorption is relatively small, making it possible to study even $1 \mathrm{~mm}$ thick samples in transmission geometry. The diffracted beam was recorded on a two-dimensional (2-D) CCD detector (FRELON) [41] placed behind the sample. The sample was continuously rotated around the cylindrical axis perpendicular to the X-ray beam in steps of $\Delta \omega=0.25^{\circ}$ covering an angular range of $84^{\circ}$. During each rotation step a 2-D diffraction pattern was continuously recorded using an exposure time of $0.2 \mathrm{~s}$. The instrument parameters of the 3-D Xray diffraction microscope were determined using a $\mathrm{CeO}_{2}$ calibrant (NIST SRM 674b).

To study the mechanical stability of the retained austenite, the sample was mounted on a $2 \mathrm{kN}$ micro-tensile tester placed on a translation table that provided alignment of the sample in three directions with respect to the X-ray beam and $\omega$ rotation along the cylindrical axis of the sample (the loading direction was along the sample axis). The samples were aligned with the top mark parallel to the frame of the tensile tester. For each deformation step, the strain was held constant during a complete set of measurements for the full $\omega$ range. The mechanical stability of the austenite phase was studied at selected temperatures of 293, 213

Table 1

Chemical composition of the TRIP steel in wt. $\%$ with balance Fe.

\begin{tabular}{lllll}
\hline $\mathrm{C}$ & $\mathrm{Mn}$ & $\mathrm{Si}$ & $\mathrm{Al}$ & $\mathrm{P}$ \\
\hline 0.218 & 1.539 & 0.267 & 1.75 & 0.018 \\
\hline
\end{tabular}




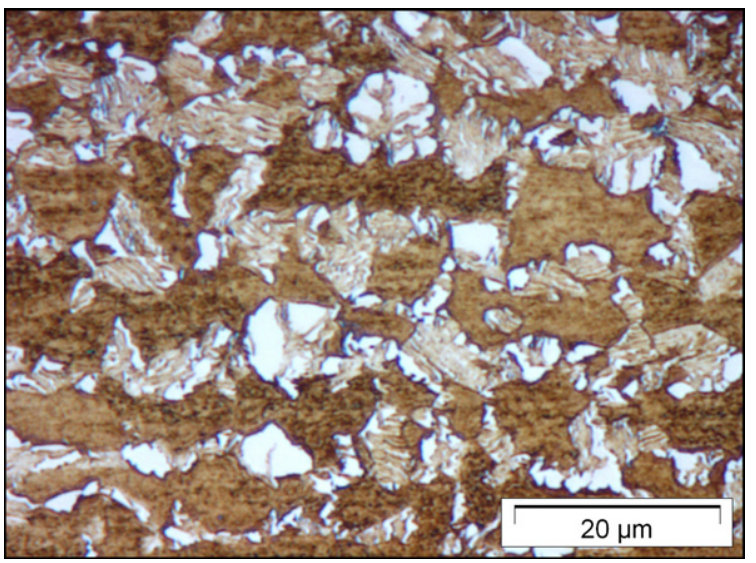

Fig. 1. Optical micrograph of the low-alloyed TRIP steel (etched by LePera). The room temperature multiphase microstructure contains a metastable austenite phase (white) within a matrix of ferrite (dark brown) and bainite (light brown) phases.

and $153 \mathrm{~K}$. The sample was cooled via the grips of the tensile tester by a flow of cold $\mathrm{N}_{2}$ gas. During cooling additional XRD patterns were recorded every $10 \mathrm{~K}$. The temperature was regulated by a temperature controller (Oxford Instruments). The tester and cooling system were placed in a borosilicate glass dome put under vacuum $\left(10^{-5} \mathrm{mbar}\right)$. Possible variations in sample-detector distance during deformation were checked by analyzing of the X-ray diffraction pattern of a calibrant placed on the sample surface.

\subsection{Data analysis}

The measured data consisted of a series of 2-D diffraction patterns as a function of temperature, sample elongation and $\omega$ angle. The 2-D diffraction patterns for the complete $\omega$ range covered in this experiment were summed.
Afterwards, an integration over the azimuthal angles at constant scattering angle was performed using the FIT2D software package [42] to obtain the corresponding onedimensional (1-D) diffraction patterns. A Rietveld refinement of the resulting 1-D X-ray diffraction patterns was performed using the Fullprof package [43] in order to determine the phase fraction and lattice parameter of the constituent phases as a function of the macroscopic strain. Fig. 3 shows two examples of the 2-D X-ray diffraction patterns with the corresponding 1-D patterns analyzed by the Rietveld method before and after applying a load. Deformation leads to a reduction in intensity for the austenite peaks, and an increase in the diffraction peaks from the ferritic matrix.

In addition to the study of the average phase behavior, we also studied the change in lattice parameter of the constituent phases oriented along and perpendicular to the loading direction. The evolution of these two families of grains has been determined by studying a specific angular section of $15^{\circ}$ on the detector. A mask has been generated to obtain the 1-D pattern for these zones of the 2-D patterns. A fit of individual reflections to a pseudo-Voigt profile function was used in order to study the stress partitioning between subsets of grains having specific $\{h k l\}$ plane normals oriented along and perpendicular to the loading direction [44].

A texture analysis has been performed using the MAUD software [45] to monitor the evolution of the preferred $\{h k l\}$ plane orientation with respect to the rolling (RD), normal (ND) and transverse (TD) sample directions. For each elongation step, 16 individual 2-D patterns were obtained by summing the measured data over an $\omega$ range of $5^{\circ}$. These summed patterns were then integrated over $5^{\circ}$ of the azimuth angle. The $16 \times 72$ resulting 1 -D patterns were analyzed by the Rietveld method using MAUD and the E-WIMV algorithm [46] for the texture refinement.

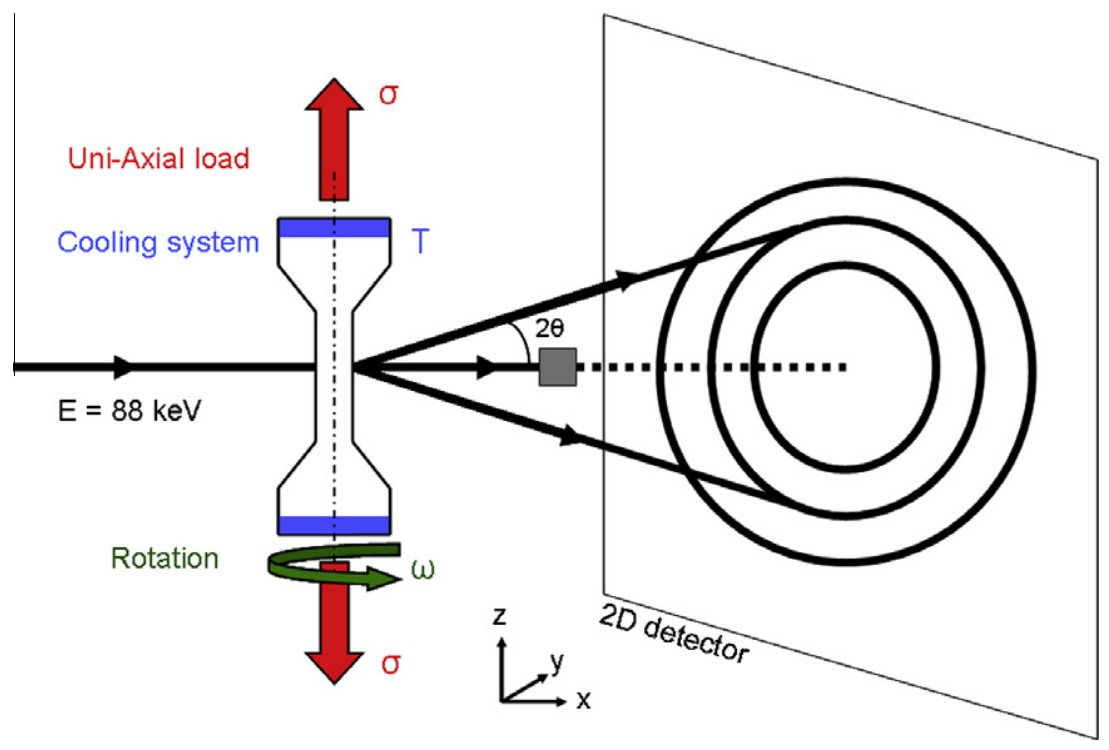

Fig. 2. Schematic representation of the experimental setup used for the high-energy microbeam X-ray diffraction experiments on low-alloyed TRIP steels. The sample is under a tensile stress $(\sigma)$ and cooled from both ends. During exposure the sample was continuously rotated around the vertical axis. 

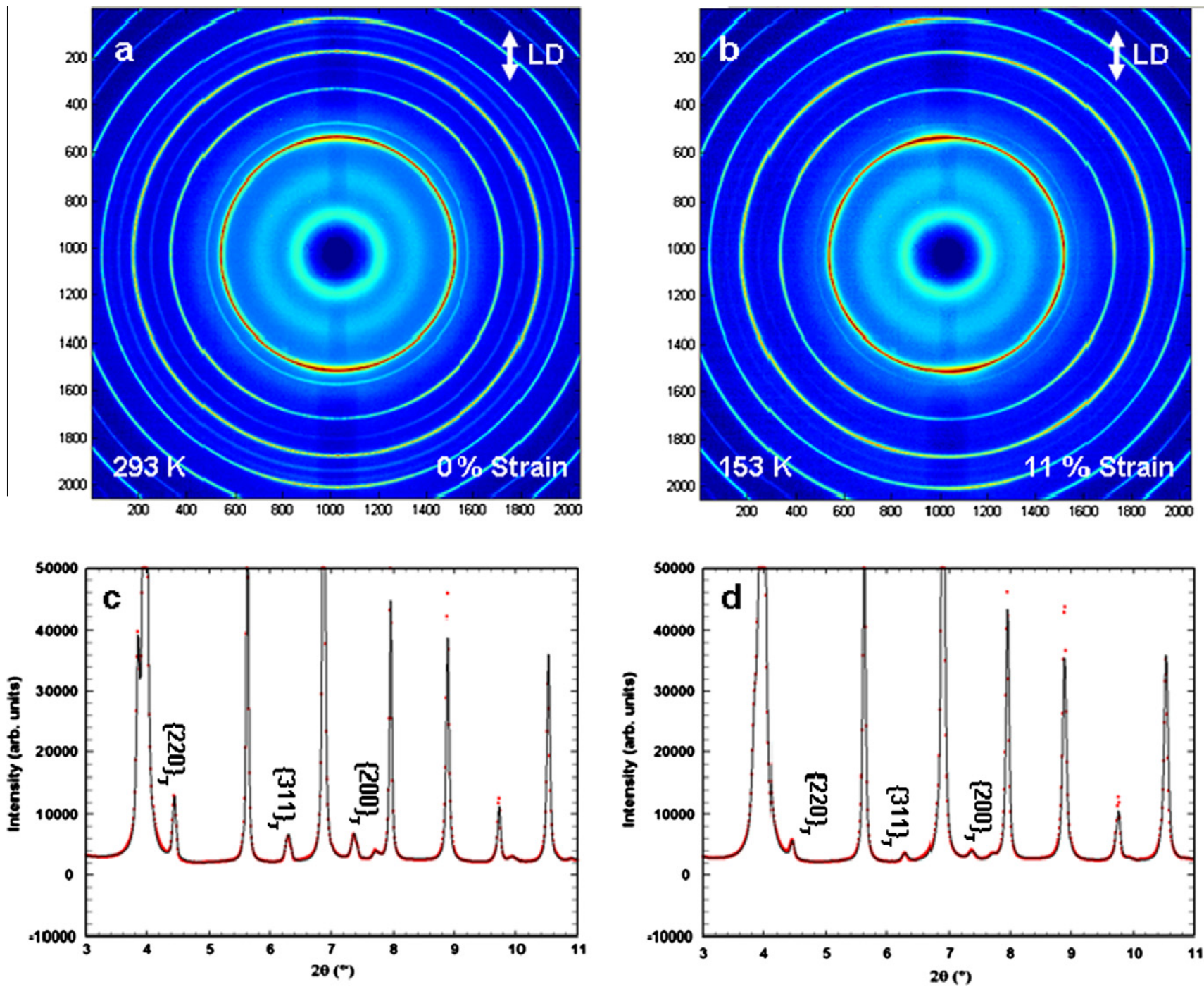

Fig. 3. 2-D X-ray diffraction patterns at (a) no strain and (b) the ultimate tensile strength (UTS). These patterns have been obtained by summing all the measured patterns for the whole $\omega$ range used in the experiments. The loading direction is indicated in the figure (LD). The 2-D patterns have been subsequently integrated over the azimuth angles to obtain the 1-D X-ray patterns as a function of the scattering angle at (c) no strain and (d) the ultimate tensile strength. The corresponding Rietveld refinement of the 1-D X-ray patterns is shown at the different strain stages.

\section{Results and discussion}

\subsection{Macroscopic behavior}

Fig. 4a shows the macroscopic (engineering) stressstrain curve of the low-alloyed TRIP steel measured stepwise at a temperature of 293, 213 and $153 \mathrm{~K}$. Each data point on the curves represents a set of X-ray diffraction measurements for the covered $\omega$-rotation range while the macroscopic strain is held constant. We recorded the diffraction patterns for a series of elongation steps up to the ultimate tensile strength. Table 2 contains the relevant parameters that characterize the mechanical behavior of the studied TRIP steel samples at the three selected temperatures. Both the yield stress and the ultimate tensile strength show an increase of more than $200 \mathrm{MPa}$ when cooling the sample from 293 to $153 \mathrm{~K}$. The uniform elongation also shows a significant increase when lowering the temperature, taking a value of about $6.6 \%$ at $293 \mathrm{~K}$ and $11 \%$ at the lowest temperature of the experiments. This effect does not agree with the expected temperature-dependent mechanical behavior of metals and multiphase alloys where plastic deformation takes place primarily by dislocation glide and dislocation interactions [47]. The reverse phenomenon observed in these TRIP steel samples with respect to the variation of the uniform elongation with temperature may be ascribed to the presence of the TRIP effect.

\subsection{Evolution of the austenite phase fraction}

The austenite phase fraction was derived from the Rietveld refinement of the 1-D diffraction patterns at the selected deformation steps and temperatures, assuming the presence 

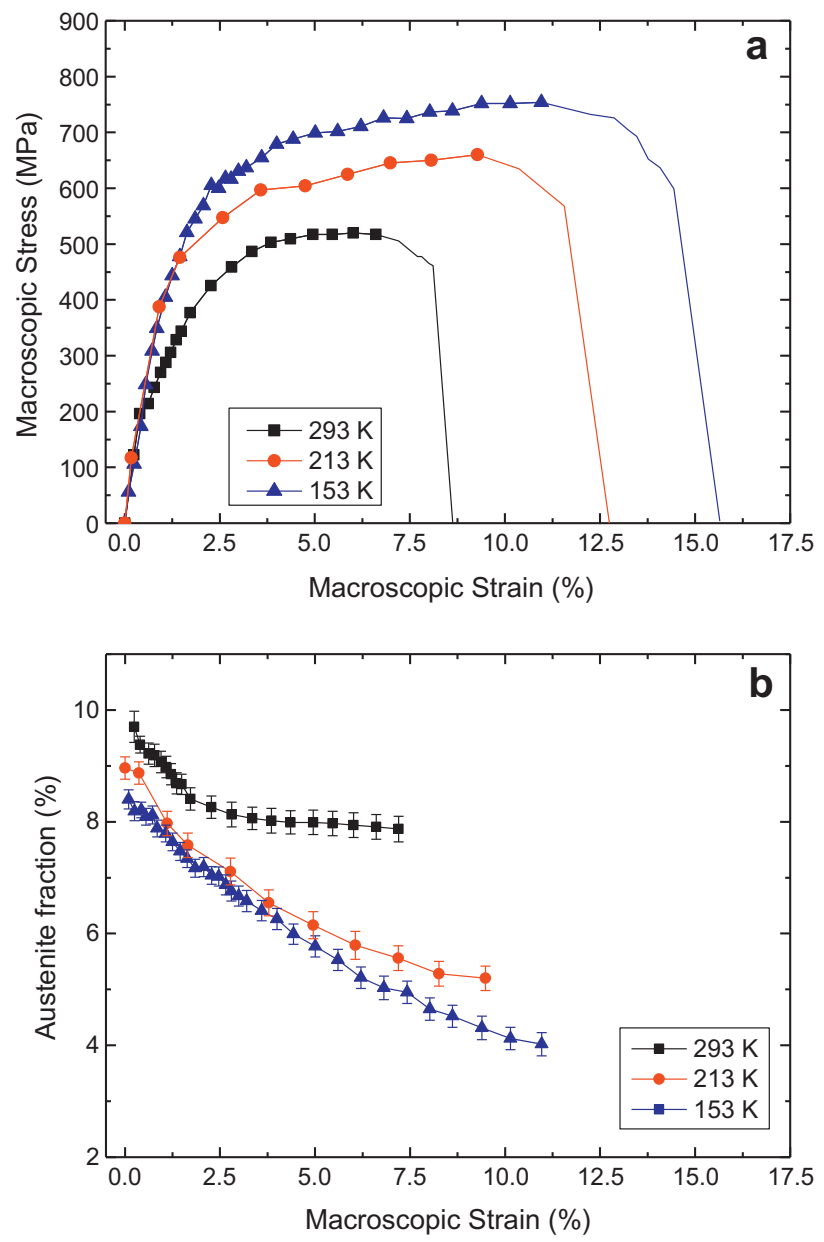

Fig. 4. (a) Macroscopic (engineering) stress-strain curves of TRIP steel measured step-wise during the in situ X-ray diffraction experiments at temperatures of 293, 213 and $153 \mathrm{~K}$. (b) Austenite fraction as a function of the macroscopic strain for the different temperatures. The variations in the initial austenite fraction are due to the transformation during cooling.

Table 2

Characteristic values for the macroscopic mechanical response of the TRIP steel at three selected temperatures.

\begin{tabular}{lllll}
\hline $\begin{array}{l}\text { Temperature } \\
(\mathrm{K})\end{array}$ & $\begin{array}{l}\text { Yield } \\
\text { stress } \\
(\mathrm{MPa})\end{array}$ & $\begin{array}{l}\text { Ultimate } \\
\text { tensile } \\
\text { strength } \\
(\mathrm{MPa})\end{array}$ & $\begin{array}{l}\text { Uniform } \\
\text { elongation } \\
(\%)\end{array}$ & $\begin{array}{l}\text { Elongation } \\
\text { at fracture } \\
(\%)\end{array}$ \\
\hline 293 & 206 & 519 & 6.61 & 8.14 \\
213 & 405 & 660 & 9.28 & 11.53 \\
153 & 471 & 754 & 10.96 & 14.42 \\
\hline
\end{tabular}

of the austenite phase within a ferritic matrix (consisting of ferrite, bainite, and the formed martensite). In previous diffraction studies $[24,31,32]$ an attempt has been made to separate the phase contributions within the ferritic matrix. For our steels the formed martensite shows no indication of a tetragonal distortion and is indistinguishable from ferrite and bainite (see also Refs. [38-40]). Fig. 3c and d shows the fitted pattern of the original material and for the ultimate tensile strength at $153 \mathrm{~K}$, respectively. The austenite reflections show a significant reduction in intensity caused by the combined effect of deformation and cooling.
Table 3

Austenite fraction for the TRIP steel measured for different strain stages at three selected temperatures.

\begin{tabular}{llll}
\hline $\begin{array}{l}\text { Temperature } \\
(\mathrm{K})\end{array}$ & $\begin{array}{l}\text { Initial } \\
\text { austenite } \\
\text { fraction } \\
(\%)\end{array}$ & $\begin{array}{l}\text { Austenite fraction } \\
\text { after cooling } \\
(\%)\end{array}$ & $\begin{array}{l}\text { Austenite fraction } \\
\text { at fracture } \\
(\%)\end{array}$ \\
\hline 293 & $9.8(3)$ & - & $8.0(2)$ \\
213 & $9.4(2)$ & $9.0(2)$ & $4.7(2)$ \\
153 & $9.5(2)$ & $8.4(2)$ & $3.9(2)$ \\
\hline
\end{tabular}

Fig. $4 \mathrm{~b}$ shows the austenite fraction as a function of the macroscopic strain at the selected temperatures. The difference in the initial austenite fraction at the selected temperatures is caused by the austenite-to-martensite transformation during cooling. The austenite fraction decreases progressively with increasing strain due to the mechanically induced austenite transformation. At all studied temperatures the austenite starts to transform well before the macroscopic yield stress is reached. The stability of the retained austenite phase strongly depends on the chemical composition and the applied heat treatment. It was found that for short bainitic holding times the least stable austenite grains can be destabilized by cooling [39] or by adding strain energy in the elastic regime [38]. At room temperature the austenite fraction decreases continuously (by maximum $1.8 \%$ ) for strains up to $2.5 \%$ and then remains roughly constant until fracture. At lower temperatures the transformation continues until fracture. As indicated in Table 3 the amount of austenite transformed by deformation is $4.3 \%$ at $213 \mathrm{~K}$ and $4.5 \%$ at $153 \mathrm{~K}$. At fracture a finite amount of austenite is still present and cannot be transformed mechanically for these experimental conditions. The increase in the austenite fraction transformed by deformation at lower temperatures shows a strong correlation to the increase in maximum elongation. The TRIP effect clearly becomes more effective at lower temperatures. This observation is consistent with recent temperature-dependent studies on the austenite stability above [48] and below [49] room temperature.

Prior to the deformation at 213 and $153 \mathrm{~K}$ the material was cooled from room temperature. In order to evaluate the austenite stability as a function of temperature a diffraction pattern was collected every $10 \mathrm{~K}$ during the cooling process. Fig. 5 shows the austenite fraction as a function of temperature during continuous cooling from room temperature to $153 \mathrm{~K}$. The austenite fraction decreases gradually when the temperature is lowered and reached a constant value below $180 \mathrm{~K}$. This is consistent with earlier observations [24]. After cooling, $0.4 \%$ of austenite has transformed at $213 \mathrm{~K}$ and $1.1 \%$ at $153 \mathrm{~K}$ (see Table 3 ).

\subsection{Relative change in lattice parameter}

In addition to the austenite phase fraction, we can simultaneously analyze the carbon enrichment of the remaining austenite from the relative change in lattice parameter during cooling. At room temperature, the lattice parameter of austenite depends on the chemical composition according to $[24,50]$ : 


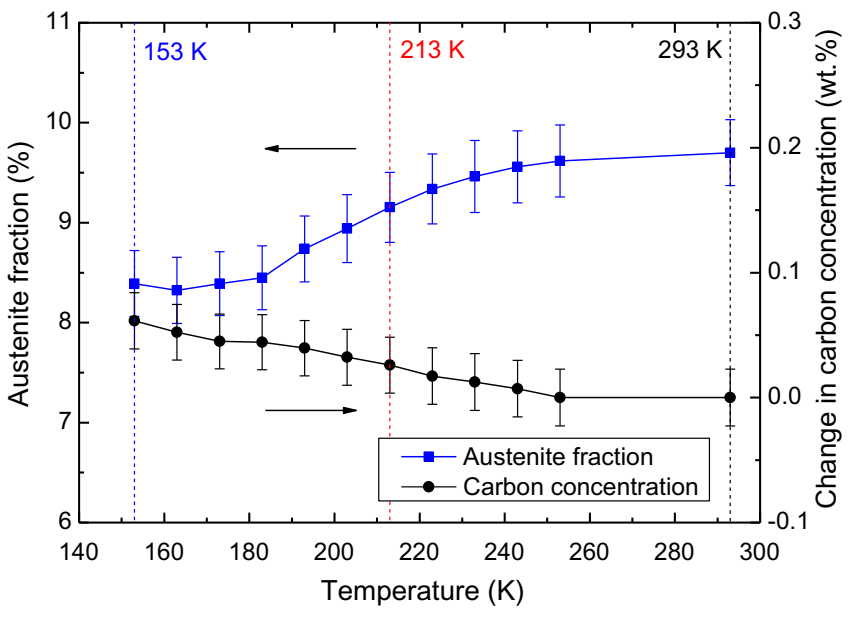

Fig. 5. Phase fraction and carbon enrichment of the austenite as a function of the temperature during cooling from 293 to $153 \mathrm{~K}$. The increase in the average carbon content in the remaining austenite is caused by the preferred transformation of the less stable austenite grains.

$a_{\gamma}=3.556+0.0453 x_{c}+0.00095 x_{M n}+0.0056 x_{A l}$

where $a_{\gamma}$ is the austenite lattice parameter in $\AA$ and $x_{c}, x_{M n}$ and $x_{A l}$ are the alloying concentrations in wt.\%. The presence of $\mathrm{Si}$ and $\mathrm{P}$ is considered to have a negligible effect on the lattice parameter of austenite. Using this equation and the measured initial lattice parameter, the carbon content at room temperature amounts to 1.31(2) wt.\%. During cooling the austenite lattice parameter is affected by the thermal contraction. Below room temperature the thermal contraction of austenite shows a coefficient of thermal expansion that linearly depends on temperature [21]:

$\frac{a(T)-a\left(T_{0}\right)}{a\left(T_{0}\right)}=\int_{T_{0}}^{T} \alpha(T) d T$

where $a\left(T_{0}\right)$ is the lattice parameter at room temperature $\left(T_{0}=293 \mathrm{~K}\right)$ and $\alpha(T)$ is the coefficient of hermal expansion. The thermal expansion at $T=300 \mathrm{~K}$ is equal to $16.0 \times 10^{-6} \mathrm{~K}^{-1}$ for austenite and $11.7 \times 10^{-6} \mathrm{~K}^{-1}$ for ferrite [24].

In Fig. 5 the increase in average carbon concentration in the untransformed austenite is shown as a function of temperature during cooling. These values have been obtained from the relative change in lattice parameter corrected for the thermal contraction. The average carbon concentration increases during cooling as only the least stable grains, with a lower carbon content, transform into martensite. According to Andrews' law [51] the martensite start temperature $M_{S}$ depends linearly on the carbon concentration $x_{c}$ in the austenite phase:

$M_{s}=M_{0}-A x_{c}$

where $M_{0}$ and $A$ are constants. In our previous XRD experiments on the stability of individual austenite grains [39] it was found that $M_{\mathrm{s}}$ also depends on the austenite grain size $V_{\gamma}: M_{0}=M_{s o}-B V_{\gamma}^{-\frac{1}{3}}$, where $M_{s o}$ and $B$ are constants. For our composition the experimental constants are determined to be: $M_{s o}=702 \mathrm{~K}, A=425 \mathrm{~K}$ wt. $\%^{-1}$ and
$B=475 \mu \mathrm{m} \mathrm{K}$. As the least stable grains will transform first, the average carbon concentration of the remaining austenitic fraction is higher at low temperature.

The relative change in lattice parameter due to deformation originates from the elastic strain and the carbon enrichment of the austenite resulting from the mechanically induced martensite transformation. The elastic strains have been determined by the lattice strain $\varepsilon$ for each phase [27]:

$\varepsilon=\frac{a-a_{0}}{a_{0}}$

where $a_{0}$ is the lattice parameter of the considering phase at zero deformation and $a$ the lattice parameter at a given deformation. In Fig. 6 the development of the relative change in lattice parameters is shown as a function of the applied macroscopic stress. During deformation, the load is distributed between the austenite and the ferritic matrix. In each phase the load distribution depends on the grain orientation. The grains with their plane normal oriented along the loading direction (axial) will be in a tensile condition and the ones with their plane normal perpendicular to the loading direction (radial) in compression. To distinguish the response of the axial and radial orientations for the diffracting planes we have selected the two relevant parts of the recorded 2-D diffraction patterns (see experimental section for details).

Fig. 6 shows the relative change in lattice parameter for austenite and ferrite at the selected temperatures. For austenite the relative change in lattice parameter originates from two contributions: the lattice strain and a change in average carbon content caused by the mechanically induced martensite formation. By comparing the relative change in lattice for the axial and radial orientations we can separate both contributions. The carbon enrichment has an isotropic effect, while the orientation dependence for the elastic strains is defined by the Poisson ratio $v=0.367[35,52]$. The relative change in lattice parameter due to the carbon enrichment $\varepsilon_{C}$ can now be estimated by $\varepsilon_{C}=\left[\left(\Delta a_{\perp} / a\right)+v\left(\Delta a_{\|} / a\right)\right] /(1+v)$, where $\Delta a_{\perp} / a$ and $\Delta a_{\|} / a$ are the relative changes in lattice parameter for the radial and axial orientations, respectively. The resulting lattice plane strain is now obtained by subtracting $\varepsilon_{C}$ from the relative change in lattice parameter for the axial and radial orientations. In Fig. 6 the resulting value of $\varepsilon_{C}$ is indicated by the dashed line and the lattice plane strains by the closed symbols.

Fig. 7 shows carbon enrichment $\Delta x_{\mathrm{C}}$ in the austenite obtained from the relative change in lattice parameter $\varepsilon_{C}$ and the corresponding austenite fraction as a function of the macroscopic strain at the selected temperatures. The carbon enrichment due to mechanically induced martensite formation is lower at $153 \mathrm{~K}$ than at $293 \mathrm{~K}$. As listed in Table 4 , the carbon enrichment varies from $\Delta x_{C}=0.24$ wt. $\%$ for $1.8 \%$ transformed austenite at $293 \mathrm{~K}$ to $\Delta x_{C}=0.16$ wt. $\%$ for $4.5 \%$ transformed austenite at $153 \mathrm{~K}$. The lower carbon enrichment during deformation at lower temperatures may be due to the carbon enrichment during the prior cooling step (Fig. 5). A larger 

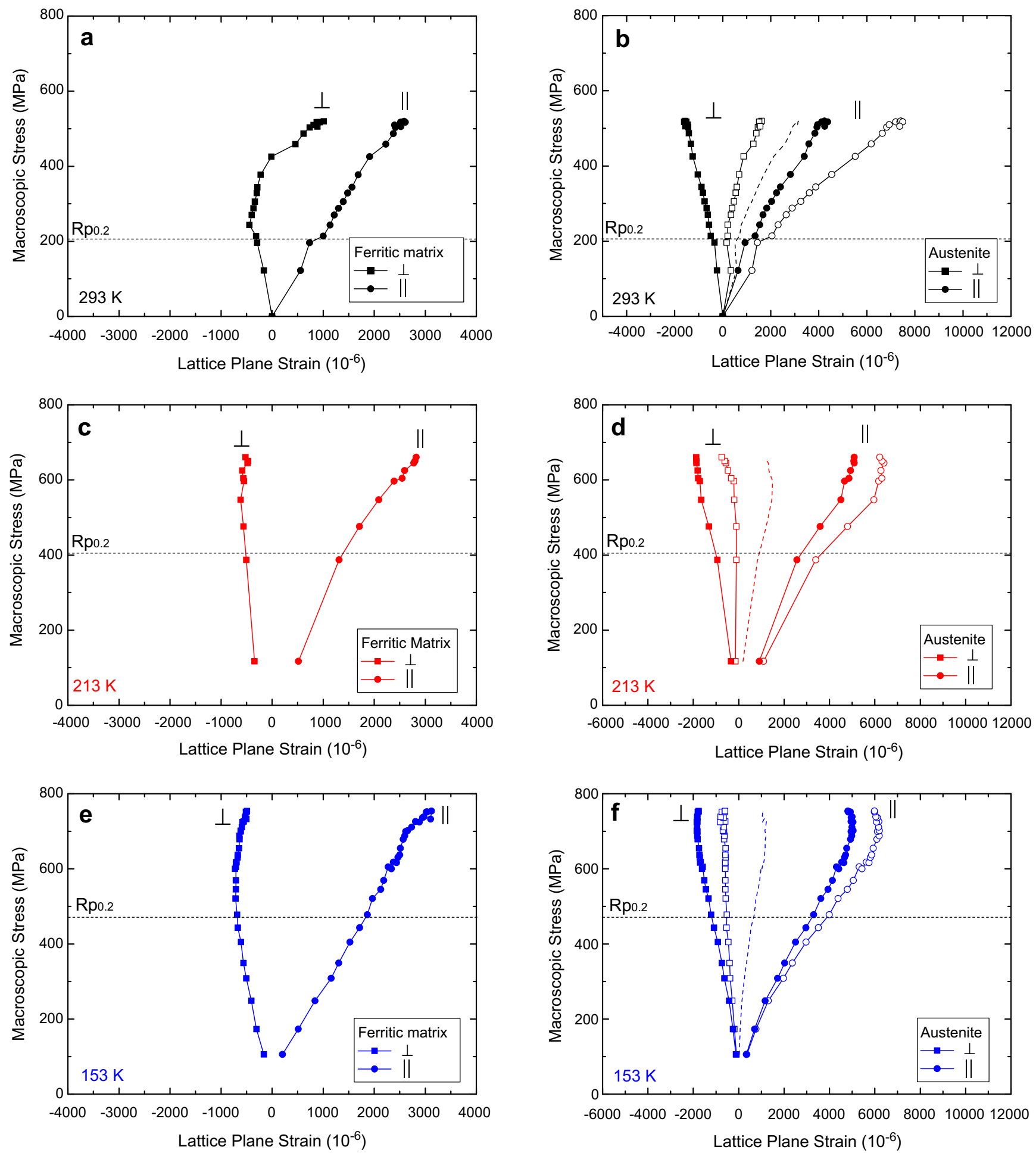

Fig. 6. Lattice plane strain of the ferritic matrix and austenite (closed symbols) as a function of the macroscopic stress for selected grain orientations at temperatures of 293,213 and $153 \mathrm{~K}$. For the axial orientation $(\|)$ the plane normal is parallel to the loading direction while for the radial $(\perp)$ direction it is perpendicular to the loading direction. For austenite the open symbols correspond to the relative change in lattice parameter $(\Delta a / a)$. This change is due to the elastic strains and the carbon enrichment. Both contributions have been separated by using the Poisson ration for austenite (see text). The effect of carbon enrichment $\left(\varepsilon_{C}\right)$ is indicated by the dashed line. The horizontal dotted lines correspond to the macroscopic yield point $\left(R_{\mathrm{p} 0.2}\right)$.

amount of austenite transformation did not result in a higher carbon enrichment. Even though we observe a continuous austenite transformation up to the maximum uniform elongation for temperatures of 213 and $153 \mathrm{~K}$ no further carbon enrichment is observed for macroscopic strains beyond $\approx 2.5 \%$.

In Fig. 6a and b the obtained lattice strain is shown for austenite and the ferritic matrix at room temperature. Below 

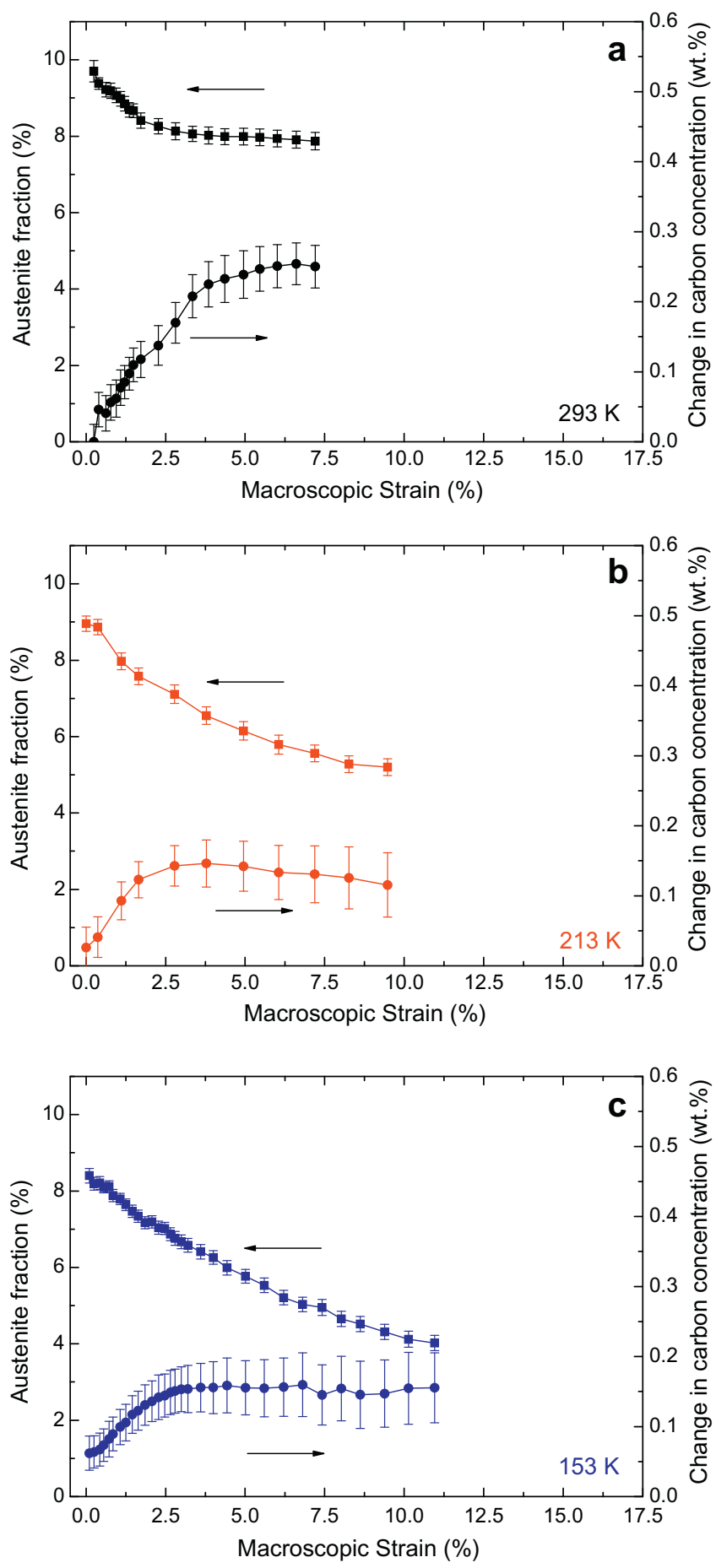

Fig. 7. Austenite fraction and carbon enrichment as a function of the macroscopic strain at a constant temperature of 293,213 and $153 \mathrm{~K}$. The initial carbon concentration corresponds to the value after cooling.

the macroscopic yield point $\left(R_{\mathrm{p} 0.2}\right)$, the lattice plane strains of austenite and ferritic matrix evolve roughly linearly with the stress. At room temperature austenite shows a Young's modulus of $E_{\gamma}=167 \mathrm{GPa}$, while for the ferritic matrix a value of $E_{\alpha}=225 \mathrm{GPa}$ is obtained. In Fig. 6c-f the obtained lattice strain is shown for austenite and the ferritic matrix below room temperature. At the lowest temperature of $153 \mathrm{~K}$ the Young's modulus of austenite and the ferritic
Table 4

Change in the carbon concentration of austenite before and after deformation at three selected temperatures. The initial carbon content in austenite at room temperature is $1.31(2) \mathrm{wt} . \%$.

\begin{tabular}{lll}
\hline $\begin{array}{l}\text { Temperature } \\
(\mathrm{K})\end{array}$ & $\begin{array}{l}\text { Change in carbon } \\
\text { concentration after cooling } \\
(\text { wt.\%) }\end{array}$ & $\begin{array}{l}\text { Change in carbon } \\
\text { concentration at fracture } \\
\text { (wt.\%) }\end{array}$ \\
\hline 293 & - & $0.24(3)$ \\
213 & $0.03(2)$ & $0.12(4)$ \\
153 & $0.06(2)$ & $0.16(5)$ \\
\hline
\end{tabular}

matrix increases to $E_{\gamma}=185 \mathrm{GPa}$ and $E_{\alpha}=233 \mathrm{GPa}$, respectively. In Table 5 the temperature dependence of the Young's modulus is reported for both phases. Based on the reported elastic constants at room temperature [35] values of $E_{\gamma}=164 \mathrm{GPa}$ and $E_{\alpha}=134 \mathrm{GPa}$ are predicted for face-centered-cubic (fcc) and body-centered-cubic (bcc) iron, respectively. A good agreement is observed for austenite, while the difference for the ferritic matrix probably originates from the presence of bainite and the newly formed martensite. For bcc iron the temperature dependence of the elastic constants [52] indicates an increase in Young's modulus of $\approx 5 \%$ for cooling to $153 \mathrm{~K}$ in line with the observed behavior. In the plastic regime the load is redistributed over the austenite and the ferritic matrix, which is mainly a result of the austenite transformation. The deviation from linearity in the stress-strain curves is observed at all temperatures, but more pronounced below room temperature. This is probably due to the enhanced TRIP effect at low temperatures.

\subsection{Lattice plane strain for individual $\{h k l\}$ planes}

The high-energy X-ray diffraction experiments allow us to follow the load partitioning not only between the phases and their main orientations, but also for the specific $\{h k l\}$ planes of each phase. In this section, the lattice plane strains of grains having specific $\{h k l\}$ planes oriented axial and radial to the tensile direction are analyzed independently. In Fig. 8 the strain of individual $\{h k l\}$ planes is shown for each subset of grains at the studied temperatures. The plane strain $\varepsilon_{h k l}$ is defined as:

$\varepsilon_{h k l}=\frac{d_{h k l}-d_{h k l}^{0}}{d_{h k l}^{0}}$

where $d_{h k l}$ is the $d$ spacing of the diffracting $\{h k l\}$ plane and $d_{h k l}^{0}$ its unstrained value. The curves of the plane strain for austenite have been corrected for the carbon enrichment obtained from Fig. 6. Significant variations in the

Table 5

Young's modulus of the ferritic matrix and austenite at selected temperatures.

\begin{tabular}{lll}
\hline $\begin{array}{l}\text { Temperature } \\
(\mathrm{K})\end{array}$ & $\begin{array}{l}\text { Ferritic matrix } \\
(\mathrm{GPa})\end{array}$ & $\begin{array}{l}\text { Austenite } \\
(\mathrm{GPa})\end{array}$ \\
\hline 293 & $225(31)$ & $167(28)$ \\
153 & $233(6)$ & $185(7)$ \\
\hline
\end{tabular}


stiffness of all the $\{h k l\}$ planes are observed for the radial and axial orientations.

For a cubic single crystal the orientation-dependent variation in elastic strain caused by a tensile stress $\sigma$ is characterized by the cubic elastic anisotropy factor $A_{h k l}$ [53]:
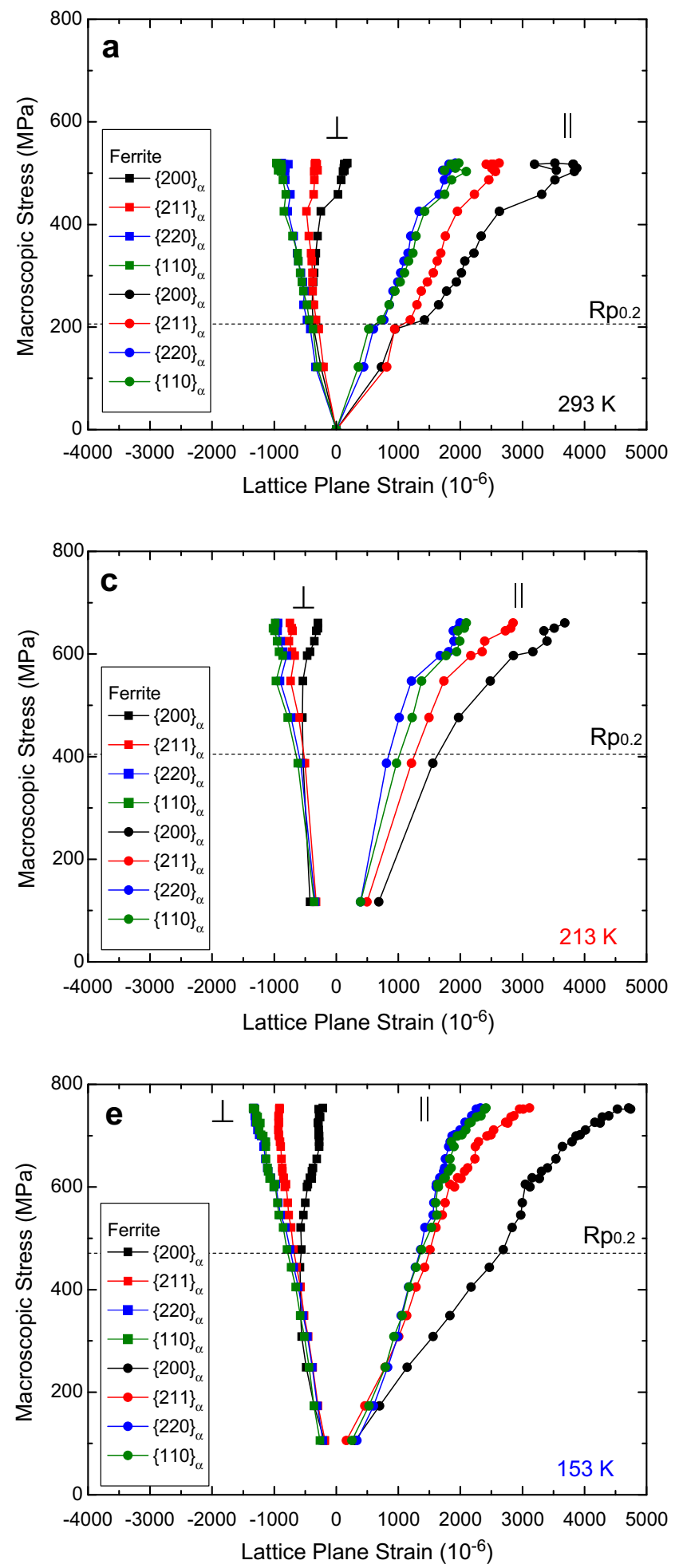

$A_{h k l}=\frac{h^{2} k^{2}+k^{2} l^{2}+l^{2} h^{2}}{\left(h^{2}+h^{2}+l^{2}\right)^{2}}$

where $h, k, l$ are the Miller indices of the diffracting plane. The elastic strain for a family of grains with a plane normal
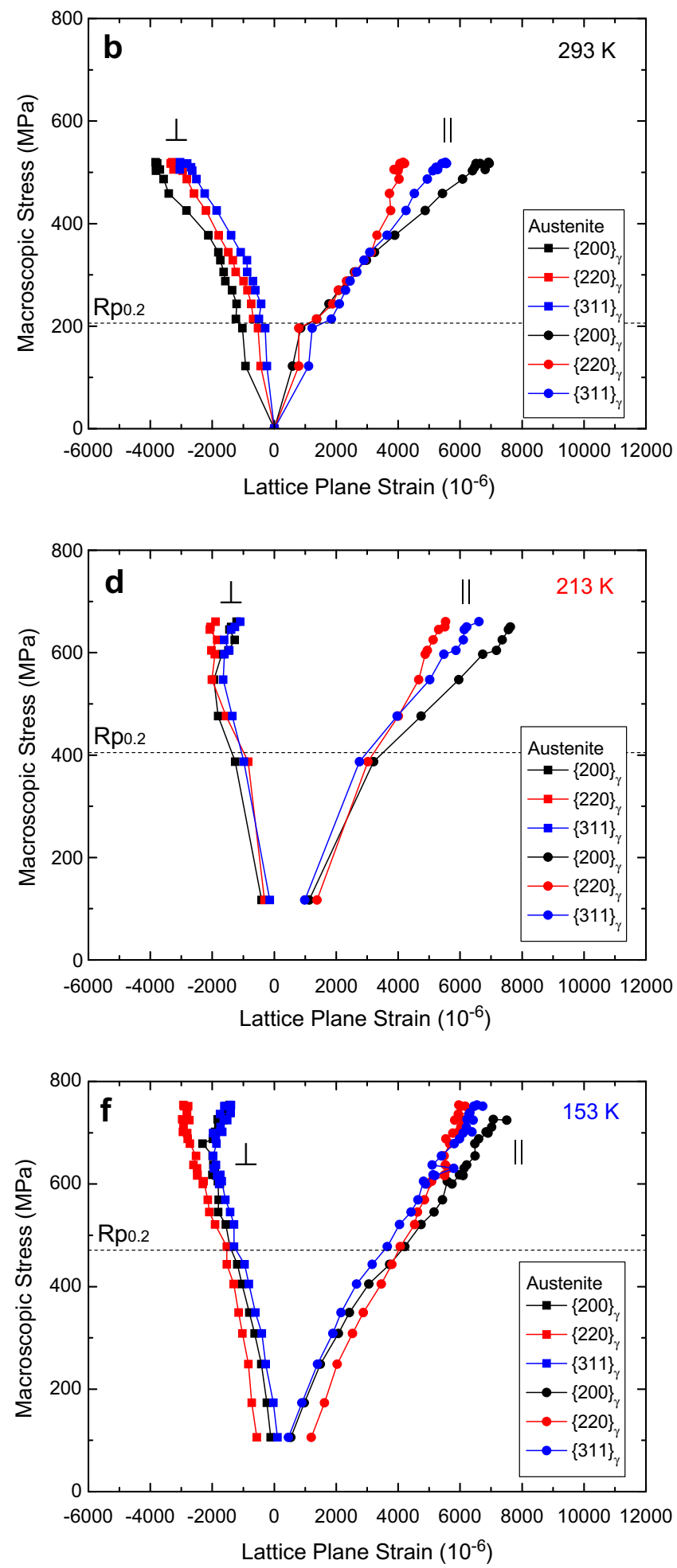

Fig. 8. Lattice plane strains of the ferritic matrix and austenite as a function of the macroscopic stress for different $\{h k l\}$ reflections separated for a plane normal oriented along and perpendicular to the tensile load. The curves of austenite have been corrected for the carbon enrichment due to the martensitic transformation. 
$\langle h k l\rangle$ aligned along $(\|)$ or perpendicular $(\perp)$ to the loading axis is given by [54]:

$\frac{\varepsilon_{h k l}^{\|}}{\sigma}=S_{11}-2\left[S_{11}-S_{12}-\frac{1}{2} S_{44}\right] A_{h k l}$

$\frac{\varepsilon_{h k l}^{\perp}}{\sigma}=S_{12}+\left[S_{11}-S_{12}-\frac{1}{2} S_{44}\right] A_{h k l}$

where $S_{i j}$ are the elastic compliances. For planes aligned with the plane normal along the loading axis, a greater value of $A_{h k l}$ implies a greater stiffness $E_{h k l}=\sigma / \varepsilon_{h k l}^{\|}$. Hence, for the austenite phase the $\langle 200\rangle$ direction is the most compliant crystallographic direction in the axial loading direction with $A_{200}<A_{311}<A_{220}\left(A_{200}=0.00, A_{311}=0.16, A_{220}=0.25\right)$ and therefore $E_{200}^{\gamma}<E_{311}^{\gamma}<E_{220}^{\gamma}$. For ferrite the $\langle 200\rangle$ directions are also the most compliant crystallographic directions in the axial loading direction with $A_{200}<A_{110}=A_{220}=A_{211}$ $\left(A_{200}=0.00, \quad A_{110}=A_{220}=A_{211}=0.25\right)$ and therefore $E_{200}^{\alpha}<E_{110}^{\alpha}=E_{220}^{\alpha}=E_{211}^{\alpha}$.

Our results shown in Fig. 8 confirm these predictions: along the loading direction the $\{200\}$ plane of the ferritic matrix is the most strained by the applied stress at all temperatures. A comparable strain development for the $\{110\}$, $\{220\}$ and $\{211\}$ planes of the ferritic matrix is observed up to the yield point. For austenite the lattice strain of the $\{200\}$ plane shows the fastest growth for increasing applied stress. The $\{220\}$ plane of austenite shows the weakest strain development for increasing applied stress, but demonstrates the highest initial strain at low stress levels. The Young's modulus for the individual $\{h k l\}$ planes is shown in Table 6 for both phases. Along the radial axis, the resulting contraction due to the axial stress also varies with the $\{h k l\}$ plane. Again the cubic anisotropy factor predicts that the stiffness of the $\{200\}$ plane is the highest for both the austenite and the ferritic matrix. The qualitative elastic response observed experimentally is well predicted by the cubic elastic anisotropy factor. However, quantitative estimates of the macroscopic $h \mathrm{kl}$ Young's modulus for the multiphase polycrystalline aggregate need to be obtained using a homogenization scheme of the single crystalline values [55].

\subsection{Austenite stability for different $\{h k l\}$ planes}

Fig. 9 shows the relative peak intensity of the $\{h k l\}$ reflections of austenite and the ferritic matrix as a function of the macroscopic stress for grains with plane normals oriented parallel to the loading direction. For the ferritic matrix the variation in peak intensity is mainly caused by grain rotation and starts around the macroscopic yield stress. For the ferritic matrix the most pronounced effect is observed for the $\{200\}$ planes oriented with the plane normals along the loading.

For the austenite phase the diffracted intensity is affected by grain orientation and the austenite transformation. The largest change in intensity is observed for the $\{200\}$ orientation, while the intensity of the $\{h h h\}$ reflection is hardly affected. Again the effect of deformation is most pronounced
Table 6

$\{h k l\}$-dependent Young's modulus $E_{h k l}$ (in GPa) for the ferritic matrix and austenite at a temperature of 293 and $153 \mathrm{~K}$.

\begin{tabular}{llllllll}
\hline Temperature & \multicolumn{2}{l}{ Ferritic matrix } & & & \multicolumn{2}{l}{ Austenite } \\
\cline { 2 - 4 }$(\mathrm{K})$ & $\{200\}$ & $\{211\}$ & $\{220\}$ & & $\{200\}$ & $\{311\}$ & $\{220\}$ \\
\hline 293 & $159(29)$ & $183(28)$ & $309(45)$ & & $161(36)$ & $121(25)$ & $160(45)$ \\
153 & $156(2)$ & $268(10)$ & $330(16)$ & & $127(7)$ & $141(4)$ & $145(7)$ \\
\hline
\end{tabular}

beyond the macroscopic yield stress, although for austenite minor variations are also observed at lower stresses. This is probably caused by the austenite transformation taking place below the macroscopic yield point. The reduction in intensity for the $\{200\},\{220\}$, and $\{311\}$ reflections is strongly enhanced at low temperatures. The preferential martensite transformation of the $\{200\}$ austenite grains is in agreement with previous diffraction studies $[31,38,56]$.

The orientation-dependent stability of the austenite phase is defined by the Schmid factor $m$, which relates the maximum resolved shear stress $\tau=m \sigma=\cos (\lambda) \cos (\phi) \sigma$ to the applied tensile stress $\sigma$, where $\lambda$ is the angle between the tensile orientation and the $\{111\}$ slip plane normal and $\phi$ the angle between the tensile orientation and the $\langle 110\rangle$ slip direction. For the diffracted intensity shown in Fig. 9 for the grains with their plane normal oriented along the tensile direction the Schmid factor $m$ can be determined. The Schmid factor amounts to: $m_{\{111\}}^{\|}=m_{\{222\}}^{\|}$ $=(2 / 3) / \sqrt{6}=0.272, \quad m_{\{311\}}^{\|}=(10 / 11) / \sqrt{6}=0.371 \quad$ and $m_{\{200\}}^{\|}=m_{\{220\}}^{\|}=1 / \sqrt{6}=0.408$ for the studied $\{h k l\}$ austenite planes. The elastic shear strain Gibbs free energy per unit volume corresponds to: $\Delta g_{\text {shear }}=\frac{1}{2} S_{44} \tau^{2}=\frac{1}{2} S_{44} m^{2} \sigma^{2}$. This shear strain energy suggests a stress dependence of the martensite start temperature of the form:

$M_{s}(\sigma)=M_{s}(0)+C m^{2} \sigma^{2}$

where $C=\left(S_{44} / 2\right)\left(d \Delta g_{v} / d T\right)^{-1}$ is a constant and $\Delta g_{v}$ the difference in Gibbs free energy per unit volume between austenite and martensite. The orientation-dependent stability of the $\{h k l\}$ diffraction planes is governed by the relative strength of the Schmid factor for the relevant planes. The reduced stress dependence of the $\{220\}$ intensity compared to the $\{200\}$ intensity is expected to be caused by the lower number of potentially active slip systems. Our proposed model considers an elastic energy criterion for the transformation of austenite into martensite, since we experimentally observe that the transformation already starts in the elastic regime. In comparison, the Patel-Cohen model [57] considers an energy criterion for the mechanical work done by the transformation that leads to a linear stress dependence of the martensite start temperature.

\subsection{Texture analysis}

A texture analysis has been performed using the MAUD software on the constituent phases for selected macroscopic strains and temperatures. Fig. 10 shows the texture evolution at characteristic stages: before cooling, after cooling, close to the yield strength and at ultimate tensile strength 

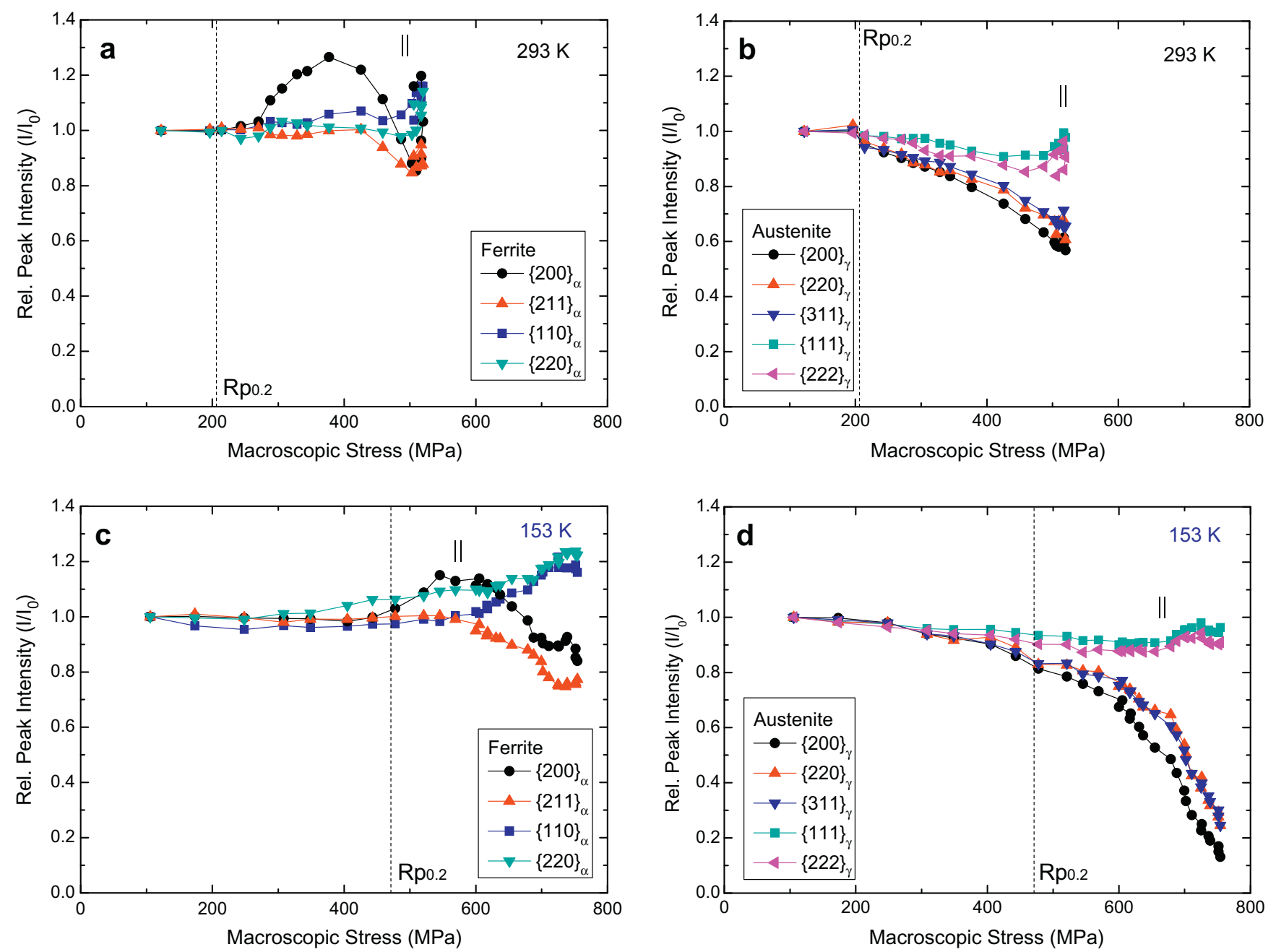

Fig. 9. Relative peak intensity of the ferritic matrix and austenite as a function of the macroscopic stress at 293 and $153 \mathrm{~K}$ for the grains with a plane normal oriented along the loading direction. The vertical dotted lines correspond to the macroscopic yield point $\left(R_{\mathrm{p} 0.2}\right)$.

(UTS). The grain orientation of the TRIP steel has been represented by inverse pole figures as a function of the rolling (RD), transverse (TD) and normal (ND) directions. The initial preferred orientation of the ferritic matrix is the $\{111\}\langle 110\rangle$. For austenite there are two components: a weak $\{110\}\langle 001\rangle$ and a strong $\{110\}\langle 111\rangle$. Cooling the material does not significantly affect the texture. The grains do not rotate during cooling although the transformation induced by cooling can activate some grain rotations. By applying the mechanical load, the $\{111\}\langle 110\rangle$ component of the ferritic matrix is further enhanced. In the austenite phase two types of texture evolution have been observed. The strong $\{110\}\langle 111\rangle$ component increases, which means that the grains rotate during the loading, while the $\{110\}\langle 001\rangle$ component tends to disappear because these austenite grains have been transformed mechanically. This is in agreement with the results of Fig. 8 and 9, where the $\{110\}\langle 001\rangle$ component decreases by straining the TRIP steel due to transformation. At low temperature the texture evolution is more pronounced than at room temperature but shows the same characteristic behavior.

\section{Conclusions}

We have performed in situ high-energy X-ray diffraction experiments at a synchrotron source in order to study the austenite stability in low-alloyed TRIP steels during tensile tests at three selected temperatures. A detailed analysis of the diffraction data reveals the relevant characteristics of the temperature-dependent austenite-to-martensite transformation during deformation. The main conclusions are as follows.

1. At lower temperatures the mechanically induced austenite transformation is significantly enhanced and extends over a wider deformation range. At room temperature the austenite transformation is observed only for strains up to $2.5 \%$, while it extends over the full deformation range at temperatures of 213 and $153 \mathrm{~K}$. At lower temperatures both the ultimate tensile strength and the elongation at fracture show an increase. The higher elongation at fracture is expected to be caused by the more efficient TRIP 
a Temperature : $293 \mathrm{~K}$

$293 \mathrm{~K}$; No strain

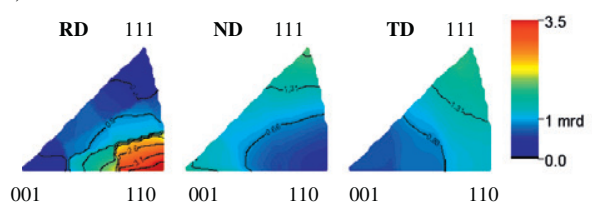

$293 \mathrm{~K}$; Yield strength
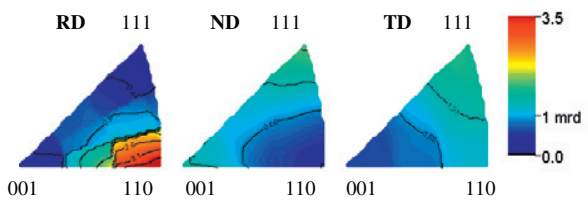

$293 \mathrm{~K}$; UTS
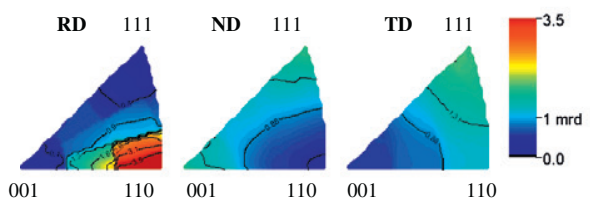

b
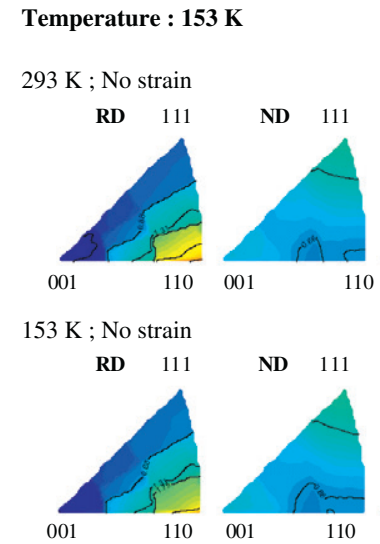

$\underline{\text { Ferritic Matrix }}$
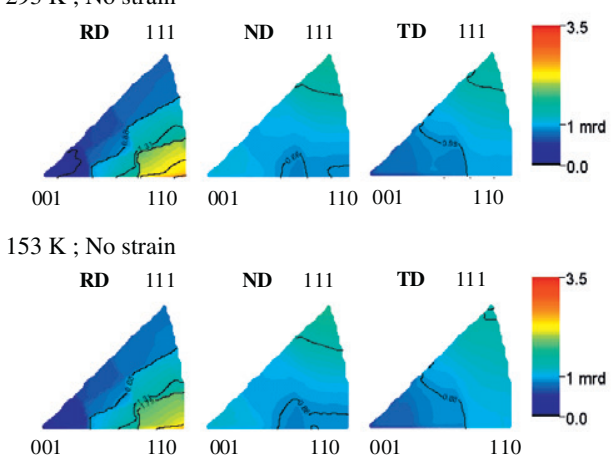

$153 \mathrm{~K}$; Yield strength
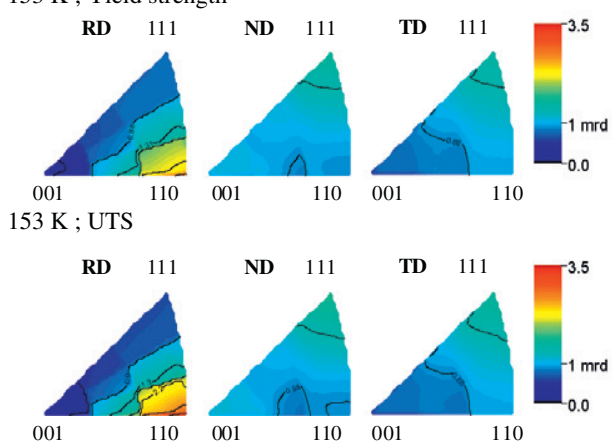
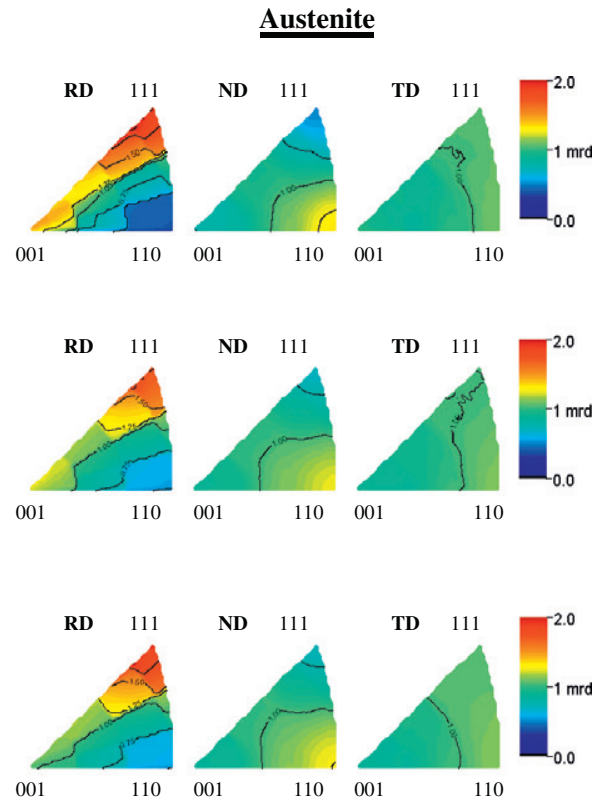

Austenite
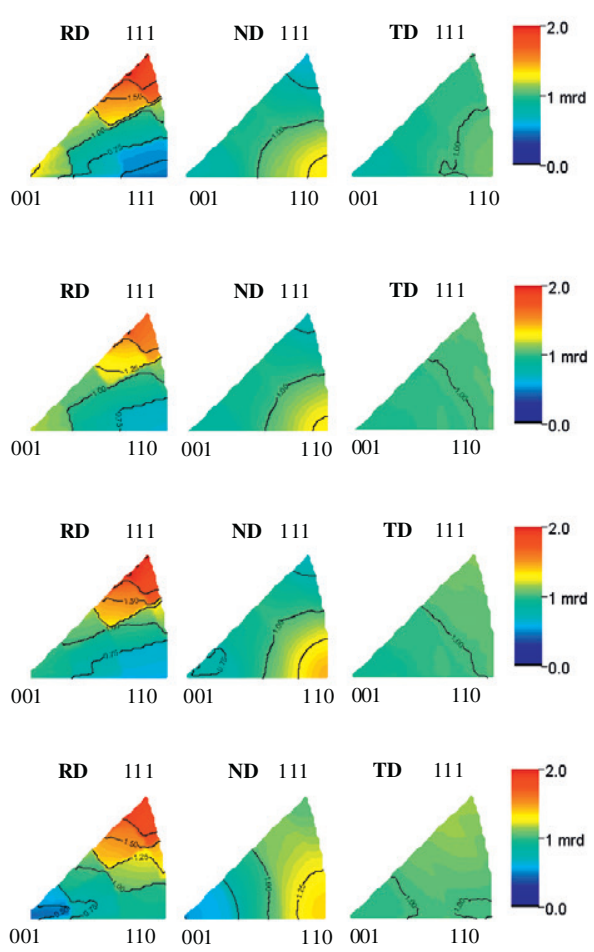

Fig. 10. Texture evolution of the ferritic matrix and austenite represented as inverse pole figures reconstructed from the ODFs for different strain steps at a temperature of $293 \mathrm{~K}$ (a) and $153 \mathrm{~K}$ (b). The scale is in multiples of random distribution (mrd).

effect for lower temperatures. At all temperatures the austenite transformation starts well below the macroscopic yield stress.

2. By selecting subsets of grains with plane normals along and perpendicular to the tensile load we can decouple the carbon enrichment in the austenite and the elastic phase strain from the derived relative change in lattice parameter during deformation.
3. The carbon concentration in the remaining austenite due to the progressive transformation to martensite first increases but stabilizes well before the TRIP effect is depleted.

4. In the elastic regime the probed $\{h k l\}$ planes develop different strains reflecting the elastic anisotropy of the constituting phases. The Young's modulus for the $\{h k l\}$ planes has been determined at 
room temperature and at $153 \mathrm{~K}$. At both temperatures the relative strength of the elastic strains on the $\{h k l\}$ planes is in good agreement with the predictions from the cubic elastic anisotropy factor.

5. The observed texture evolution indicates that the austenite grains oriented with the $\{200\}$ plane along the loading direction are transformed preferentially as they show the highest resolved shear stress. For increasing plastic deformation the combined preferential transformation and grain rotation results in the standard deformation texture for austenite with the $\{111\}$ component along the loading direction.

6. The mechanical stability of retained austenite in TRIP steel is found to be a complex interplay between carbon concentration in the austenite, grain orientation, load partitioning and temperature. A model is proposed to describe the effect of applied tensile stress on the $M_{\mathrm{s}}$ temperature.

\section{Acknowledgements}

We acknowledge the European Synchrotron Radiation Facility for provision of synchrotron radiation facilities and thank the beam line staff for assistance in using beam line ID11. We thank J. Sietsma for useful discussions. This research was carried out under the project number M41.5.08313 in the framework of the Research Program of the Materials innovation institute M2i (www.m2i.nl).

\section{References}

[1] Matsumura O, Sakuma Y, Takeshi H. ISIJ Int 1987;27:570.

[2] Matsumura O, Sakuma Y, Takeshi H. Scr Metall 1987;21:1301.

[3] Sakuma Y, Matsumura O, Takeshi H. Metall Trans A 1991;22:489.

[4] Sugimoto K-I, Usui N, Kobayashi M, Hashimoto S. ISIJ Int 1992;32:1311.

[5] De Cooman BC. Curr Opin Solid State Mater Sci 2004;8:285.

[6] Oliver S, Jones TB, Fourlaris G. Mat Sci Tech 2007;23:423.

[7] Kwon O, Lee K, Kim G, Chin KG. Mat Sci Forum 2010;638642:136.

[8] Zaefferer S, Olhert J, Bleck W. Acta Mater 2004;52:2765.

[9] Timokhina IB, Hodgson PD, Pereloma EV. Metall Mater Trans A 2004;35A:2331.

[10] Jacques PJ, Furnémont Q, Lani F, Pardoen T, Delannay F. Acta Mater 2007;55:3681.

[11] Dan WJ, Zhang WG, Li SH, Lin ZQ. Comp Mat Sci 2007;40:101.

[12] Srivastava AK, Jha G, Gope N, Singh SB. Mat Charact 2006;57:127.

[13] Skálová L, Divišová, Jandová. J Mat Proc Tech 2006;175:387.

[14] Kammouni A, Saikaly W, Dumont M, Marteau C, Bano X, Charaï A. Mat Sci Eng A 2009;518:89.

[15] Chiang J, Lawrence B, Boyd JD, Pilkey AK. Mat Sci Eng A 2011;528:4516.

[16] Jacques PJ. Curr Opin Solid State Mater Sci 2004;8:259.

[17] Traint S, Pichler A, Hauzenberger K, Stiaszny P, Werner E. Steel Res 2002;73:259.

[18] Suh DW, Park SJ, Oh CS, Kim SJ. Scripta Mater 2007;57:1097.

[19] Jacques PJ, Girault E, Harlet Ph, Delannay F. ISIJ Int 2001;41:1061.

[20] Jun HJ, Park SH, Choi SD, Park CG. Mat Sci Eng A 2004;379:204.
[21] Jimenez-Melero E, van Dijk NH, Zhao L, Sietsma J, Offerman SE, Wright JP, et al. Acta Mater 2007;55:6713.

[22] Zhao L, van Dijk NH, Brück E, Sietsma J, van der Zwaag S. Mat Sci Eng A 2001;313:141.

[23] Blondé R, Jimenez-Melero E, van Dijk NH, Brück E, Zhao L, Sietsma J, et al. Solid State Phenom 2011;172-174:196.

[24] van Dijk NH, Butt AM, Zhao L, Sietsma J, Offerman SE, Wright JP, et al. Acta Mater 2005;53:5439.

[25] Kruijver S, Zhao L, Sietsma J, Offerman E, van Dijk N, Margulies L, et al. Steel Res 2002;73:236.

[26] Park KK, Oh ST, Kim DI, Han JH, Han HN, Park SH, et al. Mat Sci Forum 2002;408-412:571.

[27] Muránsky O, Šittner P, Zrnik J, Oliver EC. Metall Mater Trans A 2008;39A:3097.

[28] Jia N, Cong ZH, Sun X, Cheng S, Nie ZH, Ren Y, et al. Acta Mater 2009;57:3965.

[29] Jung J, Kim H, De Cooman BC. ISIJ Int 2010;50:620.

[30] Tomota Y, Tokuda H, Adachi Y, Wakita M, Minakawa N, Moriai A, et al. Acta Mater 2004;52:5737.

[31] Asoo K, Tomota Y, Harjo S, Okitsu Y. ISIJ Int 2011;51:145.

[32] Cong ZH, Jia N, Sun X, Ren Y, Almer J, Wang YD. Metall Trans A 2009;40A:1383.

[33] Lani F, Furnémont Q, Van Rompaey T, Delannay F, Jacques PJ, Pardoen T. Acta Mater 2007;55:3695.

[34] Choi KS, Liu WN, Khaleel MA, Ren Y, Wang YD. Metall Mater Trans A 2008;39A:3089.

[35] Tjahjanto DD, Turteltaub S, Suiker ASJ, van der Zwaag S. Phil Mag 2008;88:3369.

[36] Choi KS, Liu WN, Sun X, Khaleel MA. Acta Mater 2009;57:2592.

[37] Liss KD, Yan K. Mat Sci Eng A 2010;528:11.

[38] Jimenez-Melero E, van Dijk NH, Zhao L, Sietsma J, Wright JP, van der Zwaag S. Mater Sci Eng A 2011;528:6407.

[39] Jimenez-Melero E, van Dijk NH, Zhao L, Sietsma J, Offerman SE, Wright JP, et al. Scripta Mater 2007;56:421.

[40] Jimenez-Melero E, van Dijk NH, Zhao L, Sietsma J, Offerman SE, Wright JP, et al. Acta Mater 2009;57:533.

[41] Labiche JC, Mathon O, Pascarelli S, Newton MA, Ferre GG, Curfs C, et al. Rev Sci Instr 2007;78:091301.

[42] Hammersley AP, Svensson SO, Hanfland M, Fitch AN, Hausermann D. High Pressure Res 1996;14:235.

[43] Rodríguez-Carvajal J. Physica B 1993;192:55.

[44] Daymond MR, Bourke MAM, von Dreele RB, Clausen B, Lorentzen T. J Appl Phys 1997;82:1554.

[45] Lutterotti L, Matthies S, Wenk HR. CPD Newsletter IUCr 1999;21:14.

[46] Lutterotti L, Bortolotti M, Ischia G, Lonardelli I, Wenk HR. Z Kristallogr Suppl 2007;26:125.

[47] Curtze S, Kuokkala VT, Hokka M, Peura P. Mat Sci Eng A 2011;507:124.

[48] Muránsky O, Šittner P, Zrnik J, Oliver EC. Acta Mater 2008;56:3367.

[49] Jiménez JA, Carsí M, Ruano OA, Frommeyer G. Mater Sci Eng A 2009;508:195.

[50] Scott CP, Drillet J. Scripta Mater 2007;56:489.

[51] Andrews KJ. J Iron Steel Inst 1965;203:721.

[52] Adams JJ, Agosta DS, Leisure RG. J Appl Phys 2006;100:113530.

[53] Nye JF. Physical properties of crystals. Oxford: Oxford University Press; 1985.

[54] Oliver EC. PhD Thesis, University of Manchester; 2002.

[55] Lorentzen T. In: Fitzpatrick ME, Lodini A, editors. Analysis of residual stress by diffraction using neutron and synchrotron radiation. London: Taylor \& Francis; 2003. p. 115.

[56] Oliver EC, Withers PJ, Daymond MR, Ueta S, Mori T. Appl Phys A 2002;74:S1143.

[57] Patel JR, Cohen M. Acta Metall 1953;1:531. 